$\mathbb{T}$ periodica polytechnica

Civil Engineering

$53 / 1(2009) 35,41$

doi: 10.3311/pp.ci.2009-1.05

web: http://www.pp.bme.hu/ci

(c) Periodica Polytechnica 2009

RESEARCH ARTICLE

\section{The effect of stiffness and duration parameters to the service life of the pavement structure}

Péter Bocz

Received 2009-01-19, accepted 2009-03-09

\begin{abstract}
The goal of this article is to determine the effect of various material parameters to the fatigue life of the pavement structures. Nowadays many types of mixtures can be built in the pavements, with different stiffness moduli. However, the Hungarian asphalt pavement design method can not handle that. The main cause of failure of the asphalt layers is supposed to be caused by the strains coming from the horizontal tensile stresses at the lowest level of layers. Many calculations were made with various attributes of the layers of the pavement structures i.e. subgrade, base course, binder course and surface course. After these calculations, we can clearly see which parameter of which layer is the most important to build a pavement with long fatigue life.
\end{abstract}

\section{Keywords}

asphalt $\cdot$ stiffness $\cdot$ pavement structure $\cdot$ strain $\cdot$ binder course $\cdot$ BISAR

\section{Péter Bocz}

Department of Highway and Railway Engineering, BME, H-1111 Budapest, Múegyetem rkp. 3, Hungary

e-mail: bocz@uvt.bme.hu

\section{Introduction}

The Hungarian asphalt pavement structure design operation is applied from 1992 for the pavement structure designing processes of the domestic road network elements; the design procedure is described in the technical specification of ÚT 21.202:2005 for pavement structures [1]. The basis of this method is the catalogue, which defines pavement structure types in the function of traffic and basic layer type. Although these pavement structure types (order of layers) are determined on mechanical basis, the actual mechanical characteristics of materials applied in structures are less considered, than their average values.

The mechanical design of asphalt pavement structures can be performed by constructing a multi-layer system. The mechanical behaviour of each individual layer is determined by various data being characteristic to the material of the layer, so to say, the thickness of the individual layers, as well as their stiffness moduli, Poisson-numbers, and fatigue (Wöhler-) curves.

Besides the mechanical characteristics, the friction between layers has important roles. Provided a sufficient bond is realised by adhesion between the two layers, that is to say, the layers do not „slip" on the border surface, the stresses of the pavement structure (upon the effect of the same load) will be lower. The partial bond situations can be examined beside the full friction and the full ,slip" as well.

The purpose of the article is to examine the effects of the change in the above parameters, or just a part of them, to the fatigue life of the asphalt pavement structure. The determination of parameters is tested in laboratory.

\section{The method of design implementation (BISAR com- puter software)}

The mechanical pavement structure design - by the definition of the mechanical parameters of the multi-layer system - can be performed by using usually computer software for a definitive case. From the softwares used, the program named BISAR (Bitumen Stress Analysis in Roads) is the most popular, developed by the Shell-laboratory (Amsterdam) [2].

This program is suitable to manage a maximum 10-layer sys- 
tem. The systems are defined by their mechanical and geometrical characteristics described in clause 1 . The lowest layer is regularly an infinite flexible semi-sphere, the layer thickness can not be interpreted here.

The loads are located in a coordinate system; the program is suitable for the superposition of more circle-shaped loads as well. Places defined by $x, y, z$ coordinates can be defined in the coordinate system arbitrarily, where the program examines the stress status, the compression strain and the displacements.

\section{The construction of the examined pavement struc- tures}

We have prepared the examined pavement structures upon before mentioned technical specifications marked as ÚT 21.202:2005. In accordance with the cited specification, the suitable pavement structure is to be selected from the pavement structure patterns during pavement structure designing, in the function of traffic load and basic layer to be constructed. The prescription, however, only prescribes the total thickness of basic layer and asphalt layers, it does not give detailed layer sequence. However, as the asphalt layers can be rolled only in defined thickness, the total thickness in description has to be split to further 2 or 3 layers obviously. This way the pavement structure is consisting of the following layers in our examinations [3]:

- surface course (asphalt)

- binder course (asphalt)

- upper base course (asphalt) - provided the total thickness is adequately high.

- lower base course

- subgrade

The mechanical characteristics of the individual layers are summarised in the following sub-clauses. The names of asphalt types have changed as of May 15, 2008, but in this paper the old names are used, because the examination tests were performed on old mixtures, between 2005 and 2007.

\subsection{Subgrade}

The foundation soil is an infinite semi-sphere without any defined thickness. The coefficient of stiffness means here the value of the static supporting modulus $\left(\mathrm{E}_{2}\right)$. Based on the prescription, the design load of the earthwork is less advantageous supporting value expected during the designed service life. The domestic design process considers the value of $\mathrm{E}_{2}=40 \mathrm{MN} / \mathrm{m}^{2}$ [4, 5].

In this present case the value of $\mathrm{E}_{2}$ is changed from 40 to $80 \mathrm{MN} / \mathrm{m}^{2}$ in $10 \mathrm{MN} / \mathrm{m}^{2}$ stages to state, how much the stresses change as a function of it.
Tab. 1. Characteristics of base layers applied in calculation

\begin{tabular}{cccc}
\hline Type of layer & Thickness [mm] & Stiffness [MPa] & Poisson-number \\
\hline M50 & 200 & 90 & 0.35 \\
FZKA & 200 & 135 & 0.35 \\
CKt & 150 & 2000 & 0.25 \\
CKt & 200 & 2000 & 0.25 \\
Concrete & 200 & 20000 & 0.25 \\
\hline
\end{tabular}

\subsection{Lower base course}

Layer thicknesses and coefficients of stiffness of base layers are summarised in Table 1 .

The definition of the M50 mechanical stabilisation modulus is performed by the SHELL formula [6]]. In accordance with the formula, the layer modulus depends on the modulus of the layer below (here: subgrade):

$$
E_{\text {granulated }}=E_{\text {lower_layer }} \cdot 0.2 \cdot H^{0,45}
$$

For the definition of FZKA crushed-stone base modulus, the correlation established by Barker and al. [7] that can be expressed for crushed-stone bed by the following formula:

$$
\begin{aligned}
& E_{\text {crushed-stone_base }}= \\
& E_{\text {layer_below }} \cdot\left(1+10.52 \cdot \log H_{\text {crushed-stone_base }}-\right. \\
& \left.2.10 \cdot \log E_{\text {layer_below }} \cdot \log H_{\text {crushed-stone_base }}\right)
\end{aligned}
$$

The coefficient of stiffness of CKt (sandy gravel stabilisation of hydraulically bound material mixed on site) is stated in the value of $2000 \mathrm{MPa}$; also the domestic pavement structure design process presumes this value.

The value of modulus of elasticity for the concrete base layer can be calculated from the average compression strength in accordance with the formula of concrete technology:

$$
E_{\text {hydraulic_layer }}=55000 \times \frac{R_{a v_{-} \bmod \_c o m p r}}{20+R_{a v_{-} \text {mod_compr }}}
$$

\subsection{Upper base course (asphalt)}

The material of the upper base course is asphalt (e.g. JU35 ), but more and more frequently rather binder course mixtures are used (K-22, K-22/F) also in the upper base course. Also in this current calculation, the value of the coefficient of stiffness presented in Par. 3.4 are presumed.

\subsection{Binder course (asphalt)}

The material of the binder course is mostly K-22, K-22/F mixture. One of the determination methods of the mixtures' stiffness moduli is the IT-CY (Indirect Tensile Test for Cylindrical Specimens) test [8]. In the Laboratory of Highway Engineering of the Budapest University of Technology and Economics (BME) - in connection with the road rehabilitation works in Budapest - the determination of coefficient of stiffness for a number of asphalt mixtures has been performed by IT-CY test. The test temperature was $10^{\circ} \mathrm{C}$, based on the equivalent temperature of 
Tab. 2. Determination of stiffness for asphalt materials applied in the calculations

\begin{tabular}{lllll}
\hline & & \multicolumn{3}{c}{ Stiffness [MPa] } \\
\cline { 3 - 5 } $\begin{array}{l}\text { Type of mixture } \\
\text { (old Hungarian name }\end{array}$ & $\begin{array}{l}\text { Number of } \\
\text { nnew name]) }\end{array}$ & $\mathrm{E}_{\text {average }}$ & $\begin{array}{c}\text { Standard devia- } \\
\text { tion }(\sigma)\end{array}$ & $\mathrm{E}_{\text {min }}$ \\
$\mathrm{E}_{\text {ave }}+1,64 \sigma$ & $\mathrm{E}_{\text {max }}$ \\
AB-11/F [AC 11 (F) surface] & mixtures & & $1,64 \sigma$ & 10771 \\
K-22/F [AC 22 (F) binder] & 57 & 12825 & 1594 & 12232 \\
\hline
\end{tabular}

the Hungarian pavement design process [5]. Based on this, the coefficient of stiffness for $\mathrm{K}-22 / \mathrm{F}$ has been determined on probability basis (see Table 2).

\subsection{Surface course (asphalt)}

The materials of the surface course in our current road constructions are most frequently mixtures $\mathrm{AB}-11, \mathrm{AB}-11 / \mathrm{F}, \mathrm{AB}-$ 16 , AB-16/F, ZMA-11. In these calculations AB-11/F mixture is applied. The stiffness of a number of $\mathrm{AB}-11 / \mathrm{F}$ mixtures has been determined in the BME laboratory, using the IT-CY test (See Par. 3.4). Based on this, the value of the coefficient of stiffness of $\mathrm{AB}-11 / \mathrm{F}$ mixture has been determined, on probability basis (see Table 2). In the case of both asphalt layers (surface course, binder course) 3 versions of moduli were calculated, such as the average value, the minimum and maximum values belonging to $95 \%$ probability level, respectively. In these calculations asphalts made of polymer modified bitumen have not been applied, though those innovative asphalt mixtures have higher stiffness moduli [9].

\section{The applied pavement structures}

The materials with characteristics described in the previous Pars. 3.1-3.5 are applied in calculations (see Table 3). The pavement structures are constructed considering with the total asphalt layer thickness determined by the traffic load classes (in this case the traffic load classes C, D, E and K have been considered) and the base layer. The lowest and the highest applicable layer thicknesses are also to be considered:

- $\mathrm{AB}-11 / \mathrm{F}$ layer can be applied from 35 to $60 \mathrm{~mm}$ layer thicknesses;

- $\mathrm{K}-22 / \mathrm{F}$ layer can be applied from 70 to $100 \mathrm{~mm}$ layer thicknesses.

Full slip has been considered between the individual layers, with the exception of the asphalt layers; in case of this latter one, gradually different friction values have been considered $(100 \%$, $75 \%, 50 \%, 25 \%$ and $0 \%$ ).

In the course of calculation, single wheel load of $50 \mathrm{kN}$ has been considered (this is in compliance with the unit axle load of $100 \mathrm{kN}$ ) affecting in vertical direction onto the upper layer, in a circle of even distribution with radius of $R=0.15 \mathrm{~m}$ $(p=0.707 \mathrm{MPa})$.

\section{Performance calculations}

The deterioration of the asphalt layers is supposed to be caused by the strains coming from the horizontal tensile stresses at the lowest level of layers; while, for the earthwork, by the vertical compressions at the uppermost levels. Experience shows that the compression of earthwork does not reach the allowed limit values, so in this case the control of strains in the lowest level of the asphalt layers will be discussed [3]. Provided the full friction of asphalt layers has been realised, just the strains of the lowest level of the asphalt layer should be dealt with, which is certainly higher than the strains at the intermediate levels. Provided the contrary of this appears, then the strains are to be controlled in the lower levels of each asphalt layer. For the sake of this, the arising strains are to be tested by the BISAR program in the lower levels of each asphalt layer.

In the calculations, performed, for the twenty types of pavement structures in Table 3, with five types of base layers, three types of stiffness moduli in surface course, three types of stiffness moduli in binder course, five types of slip value between asphalt layers were considered; that is 4500 types of different pavement structures.

\section{The results of calculations}

\subsection{Strains in the lowest level of the surface course}

Tensile stress may only arise in the lowest level of the surface course (considering the fact that the surface course has usually lower thickness than the half thickness of the entire asphalt layer), if there is no friction between the asphalt layers; otherwise a compression stress arises. The calculations have proved this; even presuming a $75 \%$ slip (this is to say, $25 \%$ friction), only a maximum of 20-25 $\mu \varepsilon$ specific strain can be experienced, even this only in case of certain smaller total asphalt thicknesses. It can be stated this way that, during design, this criteria is to be only considered, if full slip is presumed between the asphalt layers. Such case, however, in the practice can happen, even by severe breaking of technological discipline, just in rather extreme cases. As a point of interest, however, Fig. 1 shows the surface course strains of the pavement patterns calculated with minimal layer moduli and maximal slip for several types of roadway structures. In parallel with the increase of the traffic load level (and the expected total thickness, in accordance), the strain of the lower fibre will not decrease always; the reason of this is arising from the non-constant thickness of the surface course (see Table 2). 
Tab. 3. Pavement construction structures applied during the examinations

\begin{tabular}{|c|c|c|c|c|c|c|c|c|c|}
\hline \multirow{2}{*}{ Mark } & \multirow{2}{*}{$\begin{array}{l}\text { Total } \\
\text { thickness } \\
{[\mathrm{cm}]}\end{array}$} & \multicolumn{2}{|c|}{ Layer 1} & \multicolumn{2}{|c|}{ Layer 2} & \multicolumn{2}{|c|}{ Layer 3} & \multicolumn{2}{|c|}{ Layer 4} \\
\hline & & $\begin{array}{l}\text { thickness } \\
\text { [cm] }\end{array}$ & $\begin{array}{l}\text { mixture } \\
\text { type }\end{array}$ & $\begin{array}{l}\text { thickness } \\
\text { [cm] }\end{array}$ & $\begin{array}{l}\text { mixture } \\
\text { type }\end{array}$ & $\begin{array}{l}\text { thickness } \\
\text { [cm] }\end{array}$ & $\begin{array}{l}\text { mixture } \\
\text { type }\end{array}$ & $\begin{array}{l}\text { thickness } \\
{[\mathrm{cm}]}\end{array}$ & $\begin{array}{l}\text { mixture } \\
\text { type }\end{array}$ \\
\hline M50_C & 16 & 6 & $A B-11 / F$ & 10 & $\mathrm{~K}-22 / \mathrm{F}$ & 20 & M50 & - & - \\
\hline M50_D & 19 & 4 & $A B-11 / F$ & 7 & $\mathrm{~K}-22 / \mathrm{F}$ & 8 & $\mathrm{~K}-22 / \mathrm{F}$ & 20 & M50 \\
\hline M50_E & 23 & 5 & $A B-11 / F$ & 9 & $\mathrm{~K}-22 / \mathrm{F}$ & 9 & $\mathrm{~K}-22 / \mathrm{F}$ & 20 & M50 \\
\hline M50_K & 26 & 6 & $A B-11 / F$ & 10 & $\mathrm{~K}-22 / \mathrm{F}$ & 10 & $\mathrm{~K}-22 / \mathrm{F}$ & 20 & M50 \\
\hline FZKA_C & 15 & 5 & $A B-11 / F$ & 10 & $\mathrm{~K}-22 / \mathrm{F}$ & 20 & FZKA & - & - \\
\hline FZKA_D & 18 & 4 & $\mathrm{AB}-11 / \mathrm{F}$ & 7 & $\mathrm{~K}-22 / \mathrm{F}$ & 7 & $\mathrm{~K}-22 / \mathrm{F}$ & 20 & FZKA \\
\hline FZKA_E & 22 & 4 & $A B-11 / F$ & 9 & $\mathrm{~K}-22 / \mathrm{F}$ & 9 & $\mathrm{~K}-22 / \mathrm{F}$ & 20 & FZKA \\
\hline FZKA_K & 25 & 5 & $A B-11 / F$ & 10 & $\mathrm{~K}-22 / \mathrm{F}$ & 10 & $\mathrm{~K}-22 / \mathrm{F}$ & 20 & FZKA \\
\hline CKT1_C & 13 & 4 & $\mathrm{AB}-11 / \mathrm{F}$ & 9 & $\mathrm{~K}-22 / \mathrm{F}$ & 15 & CKt & - & - \\
\hline CKT1_D & 18 & 4 & $\mathrm{AB}-11 / \mathrm{F}$ & 7 & $\mathrm{~K}-22 / \mathrm{F}$ & 7 & $\mathrm{~K}-22 / \mathrm{F}$ & 15 & CKt \\
\hline CKT1_E & 20 & 4 & $A B-11 / F$ & 8 & $\mathrm{~K}-22 / \mathrm{F}$ & 8 & $\mathrm{~K}-22 / \mathrm{F}$ & 15 & CKt \\
\hline CKT1_K & 24 & 4 & $A B-11 / F$ & 10 & $\mathrm{~K}-22 / \mathrm{F}$ & 10 & $\mathrm{~K}-22 / \mathrm{F}$ & 15 & CKt \\
\hline CKT2_C & 11 & 4 & $\mathrm{AB}-11 / \mathrm{F}$ & 7 & $\mathrm{~K}-22 / \mathrm{F}$ & 20 & $\mathrm{CKt}$ & - & - \\
\hline CKT2_D & 14 & 5 & $A B-11 / F$ & 9 & $\mathrm{~K}-22 / \mathrm{F}$ & 20 & CKt & - & - \\
\hline CKT2_E & 19 & 5 & $A B-11 / F$ & 7 & $\mathrm{~K}-22 / \mathrm{F}$ & 7 & $\mathrm{~K}-22 / \mathrm{F}$ & 20 & CKt \\
\hline CKT2_K & 23 & 5 & $A B-11 / F$ & 9 & $\mathrm{~K}-22 / \mathrm{F}$ & 9 & $\mathrm{~K}-22 / \mathrm{F}$ & 20 & CKt \\
\hline B_C & 16 & 6 & $A B-11 / F$ & 10 & $\mathrm{~K}-22 / \mathrm{F}$ & 20 & Concrete & - & - \\
\hline B_D & 18 & 4 & $A B-11 / F$ & 7 & $\mathrm{~K}-22 / \mathrm{F}$ & 7 & $\mathrm{~K}-22 / \mathrm{F}$ & 20 & Concrete \\
\hline B_E & 18 & 4 & $A B-11 / F$ & 7 & $\mathrm{~K}-22 / \mathrm{F}$ & 7 & $\mathrm{~K}-22 / \mathrm{F}$ & 20 & Concrete \\
\hline B_K & 19 & 5 & $A B-11 / F$ & 7 & $\mathrm{~K}-22 / \mathrm{F}$ & 7 & $\mathrm{~K}-22 / \mathrm{F}$ & 20 & Concrete \\
\hline
\end{tabular}

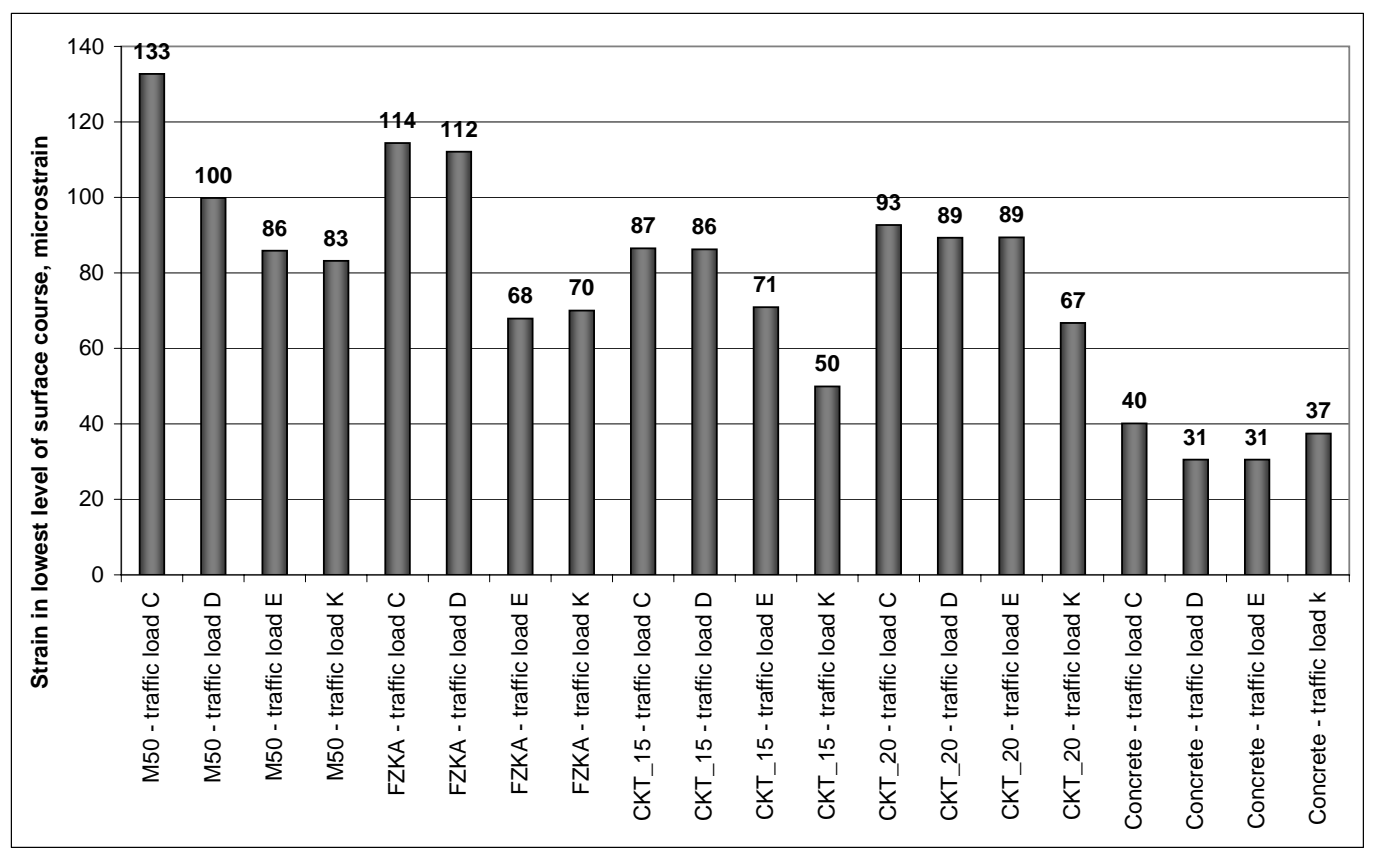

Fig. 1. Strain at the lowest level of surface course of pavement patterns

\subsection{Strains in the lowest levels of the lowest asphalt layer}

The forces arising in the lowest levels of the asphalt layer in compliance with the earlier research results and experiences are one of the main reasons of the fatigue failure of the pavement structures, this means, the forces, strains are the highest here. In this case it has to be determined that the change of which parameter of the pavement structure causes significant change in the strain.

Fig. 2 presents an example to the correlation between the stiff- ness of the asphalt layers and the strain at the lower asphalt level. Based on the experience of calculations, the lowest level strain is less dependent from the stiffness modulus of the surface course. Presuming same pavement structure(s), changing only the surface course moduli, the range of strain at the lowest level can be calculated (projected onto the average value), that can be monitored in Table 4, as a function of pavement types. It can be seen that the stronger the base layers are (CKt, concrete); the less influence the stiffness modulus of the surface course plays on the 


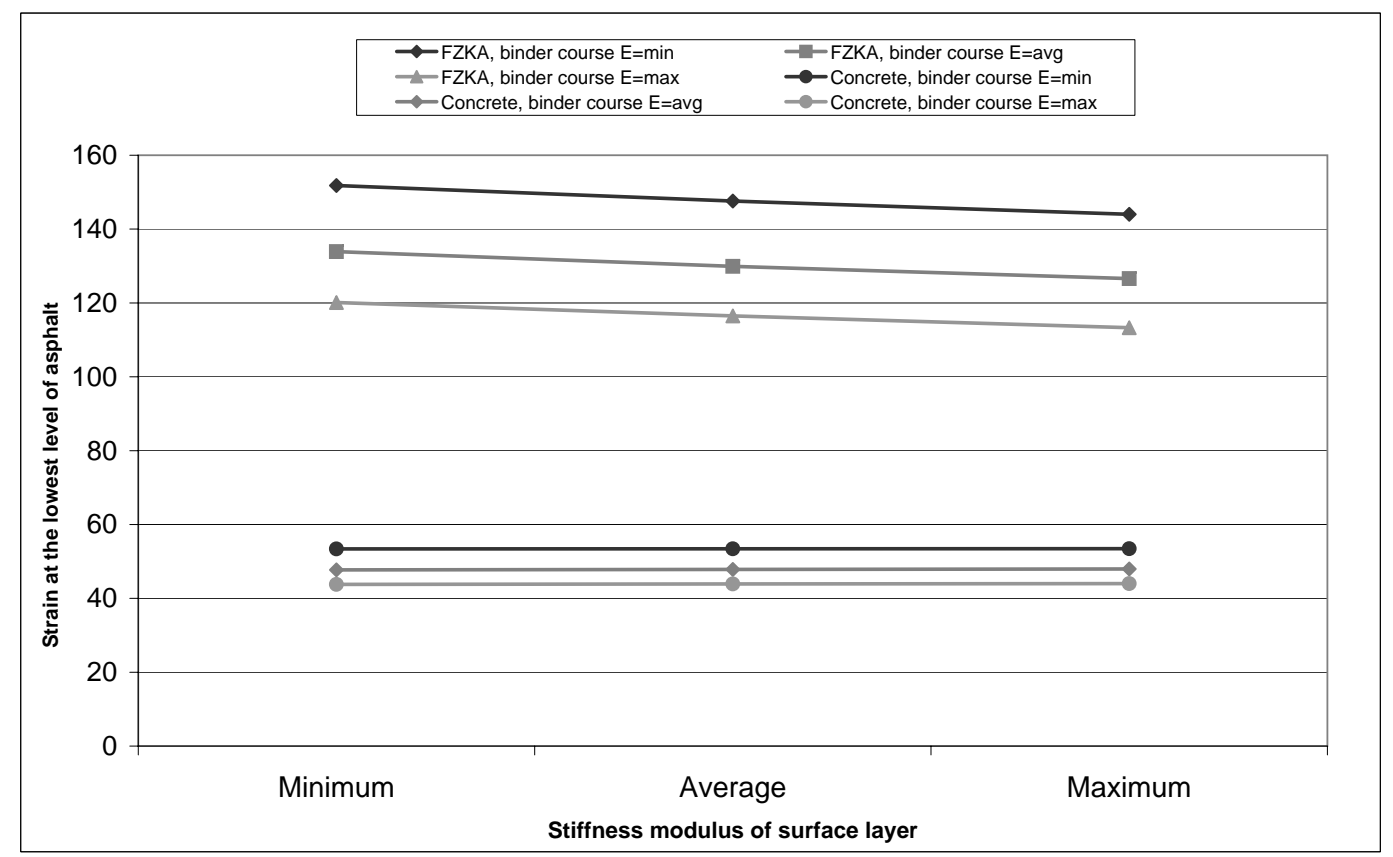

Fig. 2. Strain at the lowest level in the function of stiffness

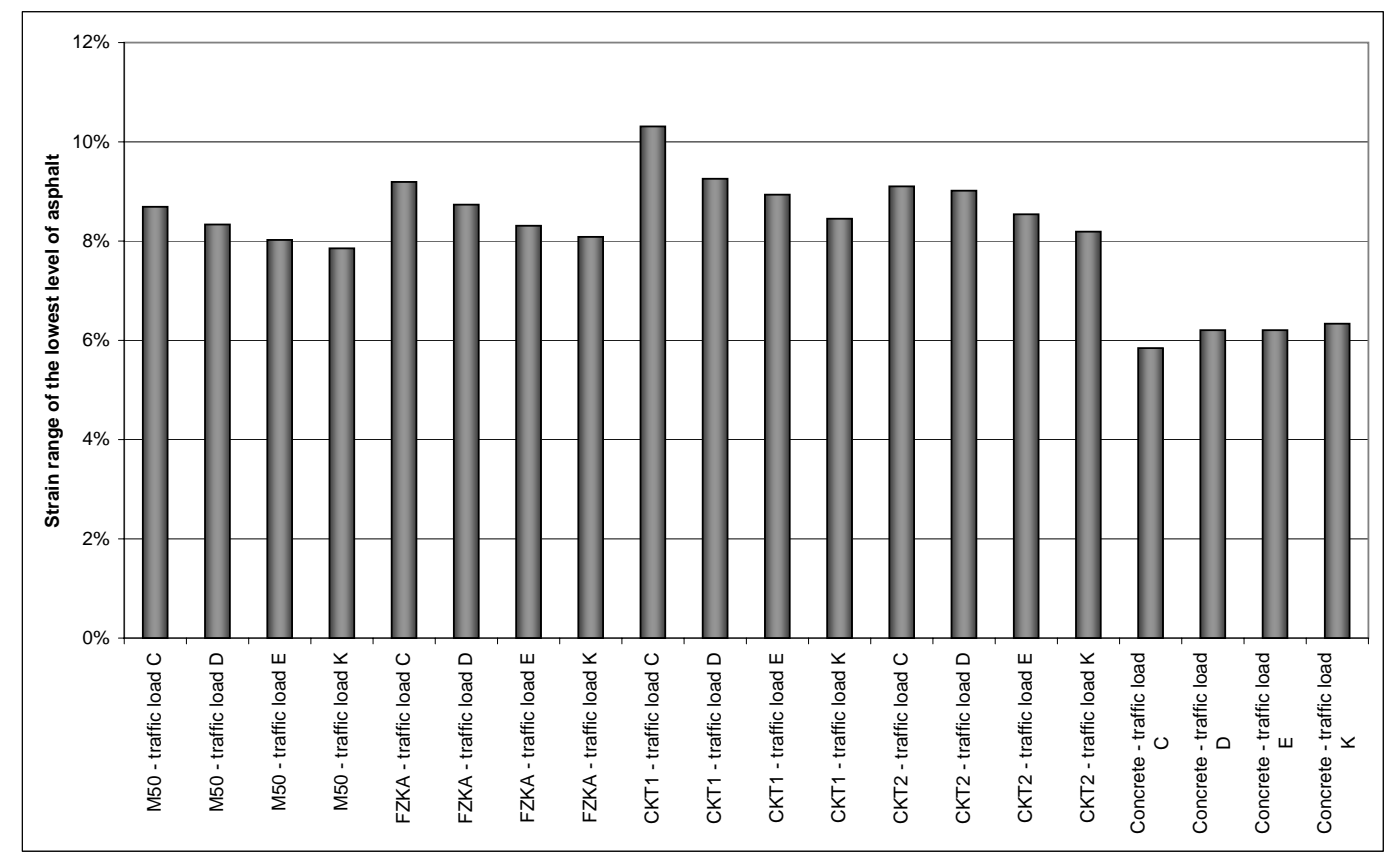

Fig. 3. Strain range of the lowest level of asphalt in the function of the earthwork stiffness in pavement patterns

pavement structure performance.

The stiffness of binder layers has a stronger effect on the performance of pavement structures. As seen in the previous Fig. 22 the deviation like this will decrease with the simultaneous increase in the stiffness of base layers (M50, FZKA, CKt, concrete), but independently from this, it remains considerable ( $\sim 15-25 \%$; Table 5). Based on calculations it is unequivocal that the improvement of the material quality and mechanical parameters of the binder course results in a positive impact to the service life of the pavement structure: the strains will be definitely smaller, and smaller strains provide longer expected service life as well.

The effect of subgrade modulus to the performance of pave-
Tab. 4. Standard deviation of the strains at the lower level as a function of surface course stiffness

\begin{tabular}{lcc}
\hline Type of base layer & Minimum range [\%] & Maximum range [\%] \\
\hline M50 & $2 \%$ & $7 \%$ \\
FZKA & $2 \%$ & $6 \%$ \\
CKt $(15 \mathrm{~cm})$ & $1 \%$ & $5 \%$ \\
CKt $(20 \mathrm{~cm})$ & $1 \%$ & $5 \%$ \\
Concrete $(15 \mathrm{~cm})$ & $-1 \%$ & $1 \%$ \\
\hline
\end{tabular}




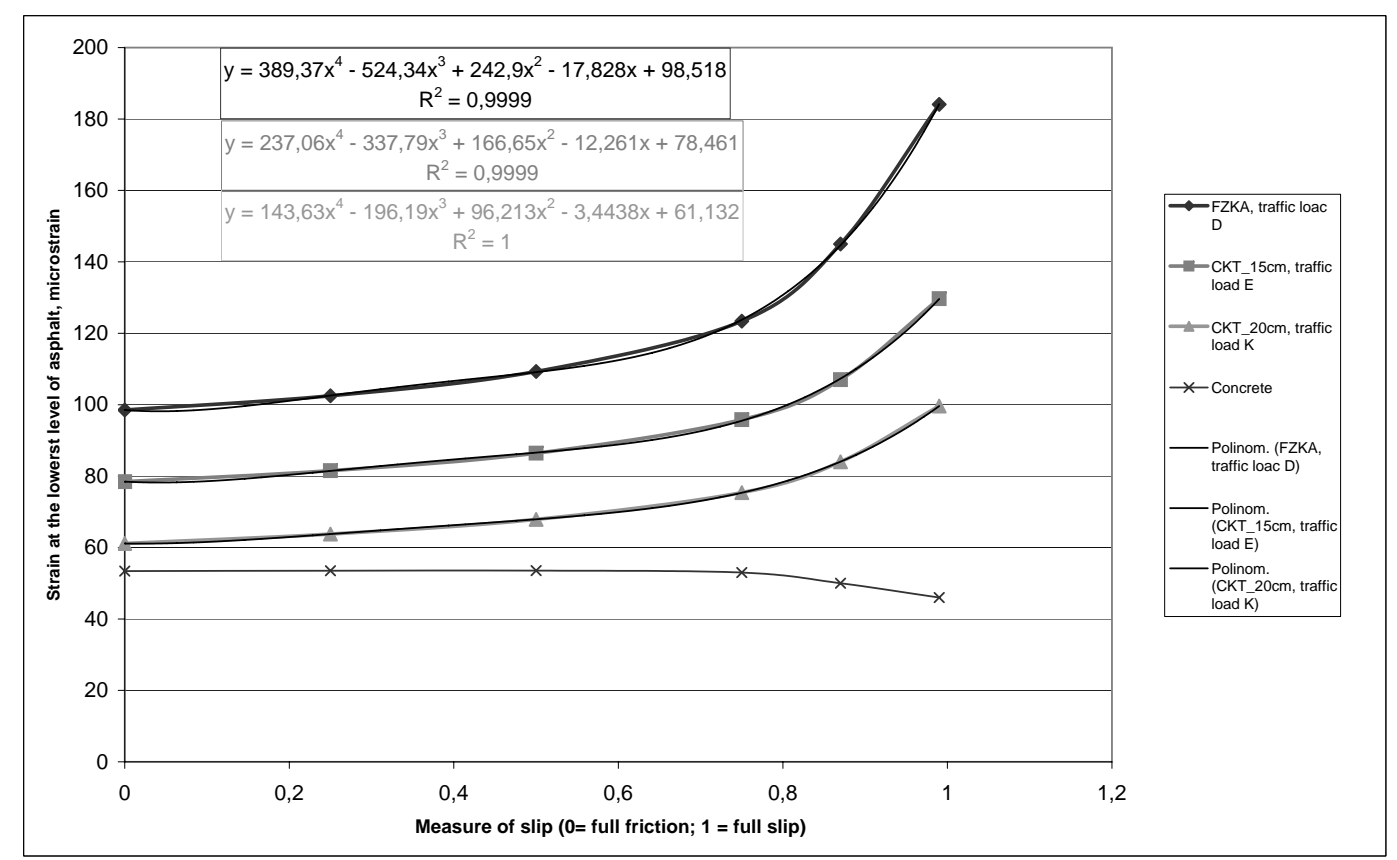

Fig. 4. Strain at the lowest level of asphalt in the function of slip between asphalt layers

Tab. 5. Standard deviation of lowest level strains as a function of binding course stiffness

\begin{tabular}{lcc}
\hline Type of base layer & Minimum range [\%] & Maximum range [\%] \\
\hline M50 & $20 \%$ & $24 \%$ \\
FZKA & $20 \%$ & $24 \%$ \\
CKt $(15 \mathrm{~cm})$ & $18 \%$ & $23 \%$ \\
CKt $(20 \mathrm{~cm})$ & $13 \%$ & $22 \%$ \\
Concrete $(15 \mathrm{~cm})$ & $14 \%$ & $18 \%$ \\
\hline
\end{tabular}

ment structure at the individual basic layer types are in accordance with the data in Fig. 3. The minimum required subgrade modulus of the earthwork is $\mathrm{E}_{2}=40 \mathrm{MN} / \mathrm{m}^{2}$, that is increased to the level of $\mathrm{E}_{2}=80 \mathrm{MN} / \mathrm{m}^{2}$ in $10 \mathrm{MN} / \mathrm{m}^{2}$ stages during calculations, controlling, whether the subgrade of higher bearing capacity will significantly decrease the level of forces arises in the pavement structures. Based on the results obtained, the range at approx. $8-10 \%$, and while in the case of concrete base layer about $6 \%$.

The condition of the friction between the binder course and the base can increase strain at the lowest asphalt level, and reduces the life of the pavement structure [10,11]. Fig. 4 shows the analysis of friction between asphalt layers. By increasing the measure of slip (\%), the strain at the lowest asphalt level sharply grows. The difference between the full bond and the full slip can be even double, while the biquadratic parabola can be applicable for the function with a good correlation. It is obvious from Fig. 4 that the strain values at the lowest level of asphalt layers above concrete base layers do not change even in case of slip, or they are small also in absolute values, respectively. In the case of weak concrete base layers, however, the asphalt layers are not designed for fatigue failure in accordance with the respective design specifications, but for the prevention of the fatigue failure of the concrete base layer.

\section{Conclusions}

Many calculations were made related to pavement structures described in the technical specification of ÚT 21.202:2005 for pavement structures. The calculations were performed by BISAR (Bitumen Stress Analysis in Roads) software developed by Shell. This software can manage multilayer systems, where layers are defined by their mechanical and geometrical characteristics.

The main goal of the calculations was to examine the change of the strains at the lower levels of asphalt layers, depending on the layers' mechanical properties. These strains are the main reason for the fatigue failure of the pavement structures.

Calculations were performed for twenty types of pavement structures, with five types of base layers, three types of stiffness moduli in surface course, three types of stiffness moduli in binder course, five types of slip value between asphalt layers. All together 4500 types of different pavement structures were analysed.

In the surface course higher strain experienced if $75 \%$ or higher slip is presumed between asphalt layers. Other parameters of the layers do not affect significantly the strain at the lowest level of the surface course. Because of this, the friction between asphalt layers is very important, so adequate technologies should be used (e.g. sufficient temperature of the lower courses during building, application of bitumen emulsion between layers).

In the lowest level of the lowest asphalt layer strains are naturally higher than in case of the surface course. Changing the subgrade stiffness or the surface course stiffness modulus does not generate high variance in strains at the lowest level. Mean- 
while changing the stiffness modulus of the binder course or the friction between layers has remarkable effect. Therefore high stiffness modulus of the binding course is necessary in pavement structures, while the stiffness modulus of the surface course does not play important role in pavement design.

\section{References}

1 Design of Road Pavement Structures and Overlay Design with Asphalt Surfacings, Hungarian Road Society - MAÚT, 2005. ÚT 2-1.202:2005.

2 De Jong D L, Peutz M G F, Korswagen A. R., Computer Program BISAR. Layered Systems under Normal and Tangential Surface Loads., Koninklijke/Shell Laboratorium, Amsterdam, 1973. External Report AMSR.0006.73.

3 BISAR 3.0 User Manual, Shell International Oil Products B.V., The Hague, 1998.

4 Nemesdy E, Az aszfaltburkolatú útpályaszerkezetek méretezésének új szabályozása Magyarországon, Közlekedésépítés- és Mélyépítéstudományi Szemle XLII (1992), no. 6.

5 _ Az új magyar típus-útpályaszerkezetek mechanikai méretezésének háttere, Közlekedésépítés- és Mélyépítéstudományi Szemle XLII (1992), no. 8 .

6 Claussen A I M, Edwards J M, Sommer P, Ugé. P, Asphalt Pavement Design. The Shell Method, Proceedings of the Fourth International Conference on the Structural Design of Asphalt Pavements, Vol. I, Ann Arbor, 1977.

7 Barker W R, Brabston W N, Chou Y T, A General System for the Structural Design of Flexible Pavements, Proceedings of the Fourth International Conference on the Structural Design of Asphalt Pavements, Ann Arbor, 1977.

8 Test methods for hot mix asphalt - Determination of Stiffness, CEN, Brussels, 2004. European Standard.

9 Sivapatham P, Beckedahl H J, Influence of the Compaction Degree of Asphalt on Rutting and Stiffness - Comparison between Conventional and Innovative Asphalts, Proceedings of the 2006 Airfield and Highway Pavement Specialty Conference, Atlanta, GA, May 3, 2006 April 30.

10 Brown S F, Brunton J M, The influence of bonding between bituminous layers, Highways and Transportation 31 (1984), no. 5, 16-17.

11 Kruntcheva M, Collop A C, Thom N H, Effect of Bond Condition on Flexible Pavement Performance, Journal of Transportation Engineering 131 (2005), 880-888, DOI 10.1061/(ASCE)0733-947X(2005)131:11(880). 